\title{
Research on Optimization of Computer Aided Multimedia Teaching
}

\author{
Mindao Xu \\ Department of Electronics Engineering, East China Jiao-tong University, Nanchang 330013, P.R.China \\ xmdao@126.com
}

\begin{abstract}
With the rapid development of information technology, computer technology has been used widely in teaching. Combining the computer aided teaching with traditional teaching can improve the quality of teaching effectively. In order to improve student learning results fast, this paper takes the natural law theory and analysis of the intrinsic reasons. Found the reliable basis for the integration of multimedia teaching and traditional teaching methods. Put forward the teaching pattern of active classroom atmosphere, and discusses the characteristics of multimedia aided teaching and traditional teaching methods respectively. Optimize the teaching process for achieving better teaching quality.

Index Terms - CAI, optimize teaching process, computer technology, quality of teaching.
\end{abstract}

\section{Introduction}

Nowadays, with information technology as the core of the computer science develop rapidly, the application of computer technology in social life at all aspects. The life of modern people have cannot do without a computer [1]. The international economic competition is the competition of talent the final. College is the cradle for cultivating talents and the important power to promote the progress of science technology, economic and social progress. Improving the quality of teaching to cultivate creative talents of high level is the responsibility of the each teacher. With the construction of teaching information unceasingly thorough, the multimedia teaching has become the preferred method of teaching [2]. The computer is as the core of multimedia technology, which in the form of pictures, vivid, rich and colorful in the classroom. Its powerful information processing and performance ability, it helps the students to abstract and process understanding and feeling, improving the efficiency of teaching, bringing the classroom teaching into new realm. The computer aided teaching has become a hot topic in electro education research and practice in China. When finding the advantages of multimedia teaching brings, also should find the problem of teaching by using multimedia. For example, reading courseware and classroom information content is too large lead to serious negative influence teaching effect. Therefore, should make the integration of multimedia teaching method and traditional teaching method. Not only abide by the tradition education culture but also effective combination of multimedia technology in education. The organic integration of the two teaching methods, deepen teaching reform, achieve leapfrog development of education quality [3]. Finally, achieved the target of education information is high input high output, high investment and high benefit. In addition, people contacts the CAI little time, might have knowledge of it not deep or deviation. According to the author's teaching practice in recent years, application of CAI, takes several suggestions on how to optimize the teaching of CAI.

\section{Problems of CAI Teaching}

In the process of teaching, we realize that using CAI teaching mainly exist the following four questions.

A. Information Maintaining Time is Short and Incoherent, Bad for Associative Memory and Absorb Information.

Demo type slide shows, one by one, at the same time, old content slides completely replaced by a new content of the slides, not like the blackboard long-term retention teaching information, such as "outline", lack of medium conditions of associative memory and thinking for the student. Once in the process of teaching, the thinking of students is interrupted. The students can produce inconsistent up and down, the feeling of scratching their heads. In addition to the classroom light is dark, easy to cause "addled" feeling, it cannot achieve the teaching purpose of make learners for effective learning [4].

\section{B. Large Amount of Information, Progress Faster, Students are Difficult to Adapt.}

CAI can reduce teacher drawing work load, blackboard writing work load, etc. Improve the teaching efficiency, but at the same time as the class information increase, the student thought in a state of high tension. Students have little carelessness, and they can't keep up. Students are difficult to adapt, and it's easy to cause the students have no time to take notes or simply don't take notes. Thus, it lost memory function and review function due to take the notes. If this situation is not reversed, it will make student difficult to keep up with the teacher's lecture schedule and the beat, and achieve adverse teaching results.

\section{Reduce the Time for Students and Teachers Directly Communication, Students' Learning Interesting is Difficulties and Durable.}

When they first got in contact with CAI, students are inspired inquisitive learning interest by the vivid pictures. The attention of students is concentrated on screen. But ignore the direct communication (words and deeds) between teachers and students in the classroom. And after all, CAI is a teaching courseware. It doesn't like entertainment spectacular, as time passes students will feel boring. Students' learning interest is hard and durable [5]. 


\section{The Process of Teaching Progress is Difficult to Control.}

Generally speaking, courseware content has already been finished. According to the different level students it is difficult for teachers learned to adjust accordingly, according to the actual situation it Make teachers difficult to changed the teaching content on general classroom.

\section{Optimization of CAI Teaching}

The application of CAI aims is to make the teaching quality and efficiency improve. In order to give full play to the advantages of CAI in the teaching process, combined with practical application of CAI, the use of CAI in the teaching process should pay attention to the following three aspects.

\section{A. Prominent Focus and Control Speed and Appropriate Information}

The use of multimedia courseware should adhere to the principle of focus, highlighting the difficulties. The knowledge which the traditional teaching means is difficult to display on the screen. But the dynamic simulation technology can come true easily. If it is not fully reflect the CAI features and advantages of the content of curriculum, please don't use CAI in class. If made the books digital simple in teaching, it will dilute the theme of teaching. That is not only bad to the improvement of teaching, but also will dampen the enthusiasm of the students on learning by multimedia. After using CAI, lead to problems of large amounts of information, fast speed. The students can not adapt at the moment, so teachers should pay attention to how transiting. If not handled properly, it will lead to side effect. At the early stage, teachers would be appropriate to reduce the classroom information. After a certain period, then according to the specific conditions, the amount of information and the speed of progress are increased appropriately. In addition, let the students prepare courses before class and review after class. Consolidating learning is an important part of making knowledge into ability after class, can guide the students to discover and innovate and achieve the second leap. Therefore, teachers should give students some representative exercises or can inspire students to further explore the question further. Guiding the students is to access a reference by library. Cultivate the ability of students' selfstudy, check the information and solve problems. Do experiments so that make learn skills and thinking develop at the same pace [6]. By theory combined with practice to improve the learning initiative.

\section{B. Organic Combination of Two Ways and Teacher Lead}

After all, CAI plays the role of auxiliary teaching only. Teachers play a leading role in the classroom teaching. The modern education technology works with traditional education technology together that can reflect its application value. If classes are students and screen sharing from first to last, it is easy to cause the students' attention to the screen. It is leading to no strong interest to learn, this state last long time will makes students feel boring. Therefore, we should give full play to teachers' leading role in teaching. Teachers should take his personality charming and interesting explanation. Infected emotion of between the teachers and the students, mobilize the students to participate in teaching actively. The good teaching effect makes positive effect on students' psychological. It is can not be replaced by any form of the electronic media. Therefore, we should give full play to the leading role of the teacher in the teaching process. For some important words and expressions, not only writing on the blackboard but also explaining in detail. In addition, teachers should be based on the content of class and specific circumstances and concise language induction and summarizes or asks questions. We discuss methods of flexible guide students to discover problems, analysis problems and solve the problem. The organic combination of the visual image of CAI teaching method with the traditional teaching method will get twice the result with half the effort [7].

\section{CAI Courseware Should Reflect the Teacher's Teaching Style \\ Every teacher has own teaching methods and} characteristics in class. Therefore, teachers developed CAI courseware should fully embody and reflect the teachers' teaching style. The use of traditional teaching methods, different teachers will get the different teaching effect on the same content. If they all follow the same pattern as a style of teaching by using CAI, Innovation will seriously restrict teachers' role and the bound of teachers. It may hinder the development of teaching. In the development of CAI courseware, each knowledge point of teaching content should be put into the library, so that every teacher can according to their own teaching style call the library contents flexible. Thereby, forming preparation system meets the teachers' teaching skills. The teaching system can make every teacher's advantages and characteristics displayed fully. Various teaching effect is formed at last.

\section{Principles of Optimization Designing}

\section{A. Design Principles of Notes}

In order to make the students harvest more in the classroom. Forget less knowledge that had learned, remember more, memory length. With the law of memory, design lecture note should take basic law. The material of the image can be remembered more easily than the text material. The meaningful material is forgotten slowly than the meaningless materials. Skilled movement is most difficult to forget. Also notice that mark the deepening of teaching materials in handouts to explain. Give full play on ideographic, expression [8]. This is very effective to review and organize activities and overcome forgetting. Therefore, the principle of the specific notes is that teaching the simple content depends on the audiovisual to carry on episodic memory, in the abstract and complicated content, not only take the multimedia teaching audio-visual but also use other ways to explain. For example, the key points in the tiny link, the traditional teaching mode writes on the blackboard with painting so that the knowledge and information are long memory [9]. We advocate that the multimedia teaching mode assistant the traditional teaching. 
Each of the new knowledge has overall and structural characteristics. Like the relationship between the overall composition of painting and local. Some meet people in characteristics, in the process of cognition with learning thinking on this principle. In order to make notes form an integral structure of knowledge, the intrinsic logic and structure of the knowledge content full presented. It emphasizes some main contents.

\section{B. Handout Scheme}

At beginning, should raise the key problem with illuminating or propose the key learning points. The end is a summary of important conclusion. The intermediate module structure is guided. Therefore, several lectures should mark media materials when it is inserted. Use courseware made by self to supplement. Multifunctional platform is used to demonstrate the real. Use the blackboard and pursuit of visual. The effect of using large screen is vivid and interesting. It must use the specific material, geometric figure or image graph to express the abstract language. It is useful to mobilize the learning enthusiasm and interest of students. It is necessary to interact with students for promoting taking notes and do homework automatically [10].

The notes should according to the logic of science to combine image with abstract to clarify the truth. Make the content classification, systematic or brief relationship combined. This is according to the flow chart of knowledge content to extend. At the same time, in the handout for each structure module to mark by the way of teaching expression. If in the supplementary courseware self-made, according to need some games module is designed. The interaction is better because the students use audio-visual learning easily fatigue and forgetfulness. If use different multimedia function or with other means to speak, can make the class lively and vitality. It caused main melody beat resonance between the teachers and students in the classroom.

\section{Conclusions}

CAI provides one new teaching means for class teaching. It has a very bright future in the education field. However, it just was the teaching aids. It can not and will not replace teachers completely. The teachers' status is always the dominant position in the teaching. Any advanced teaching method must play a role through the teachers. Multimedia teaching must be established on the basis of giving full play to teachers of the "media" function to the bright future.
Therefore, as a teacher cannot depend on teaching software. We should give full play to their initiative. We should make more effort at flexible using the soft. We research on multi method combined. In the teaching thought, teaching idea and teaching design produce breakthrough and innovation. By hard work and wits to rich and enhance the advantages of CAI further. The multimedia resources and other resources constitute the unified system of teaching resources. Finally, the goal is to improve classroom teaching quality and teaching effect. In a word, knowledge and information access to the students by teachers. The teacher control properly, students not only master the knowledge, but also the intellectual and ability can develop. Teachers should play a key role in the integration of the two teaching methods. Teachers should use the scientific courseware comprehensive in Colleges and universities to design the classroom teaching systematically, to improve teaching quality and to create a "sunny fresh classroom". This is the vital link in carrying out quality education.

\section{References}

[1] Jia, Xiaolin, et al, "Multimedia Education Resources Management Based on Service Oriented Architecture," Consumer Electronics, Communications and Networks, pp. 403-408, 2013

[2] Zhang, Hong, Xin-hua Li, and Shuhui Min, "Study on Optimization of College Multimedia Teaching Based on System Design Philosophy," Hunan Agricultural Machinery, pp. 087-091, 2011.

[3] Hu, Mingming, and Shu Xu, "Research of Multimedia Teaching on Principles of Management," IERI Procedia, pp. 666-670, 2012.

[4] Jiangang, Yi, "Optimization of Multimedia Teaching and Tearning Environment," Future Computer and Communication, pp. 137-139, 2010.

[5] Shi, Tongkun, et al, "The Applied Study of The combining Multimedia Teaching with Traditional Teaching in The Operative Procedure Teaching," Multimedia Technology, pp. 5141-5143, 2011.

[6] Zhang, Yu, Jun Jin, and Yongzhen Li, "Teaching Design and Multimedia Teaching Resources Development Using Information Processing The ory," E-Health Networking, Digital Ecosystems and Technologies, pp. 307-310, 2010.

[7] Zhang, Chengyi, and Xi Chen, "Use of Multimedia in Gross Infective Pathogen Experimental Teaching," Procedia Engineering, pp. 64-67, 2012.

[8] Yang, Xiu-Ping, et al, "Optimization and Application of Multimedia Teaching Means of Specialized Courses in Engineering," Energy Procedia, pp.1878-1884, 2012.

[9] Yi, Lin, "The Integration and Optimization of the Multimedia Teaching and Traditional Teaching Methods," Mechanical Management and Development, pp.90-93, 2011.

[10] Zhao, Cuijun, and Guoquan Jiang, "An application multimedia to the teaching of biostatistics," Education Technology and Computer, pp.1334-1337, 2010. 